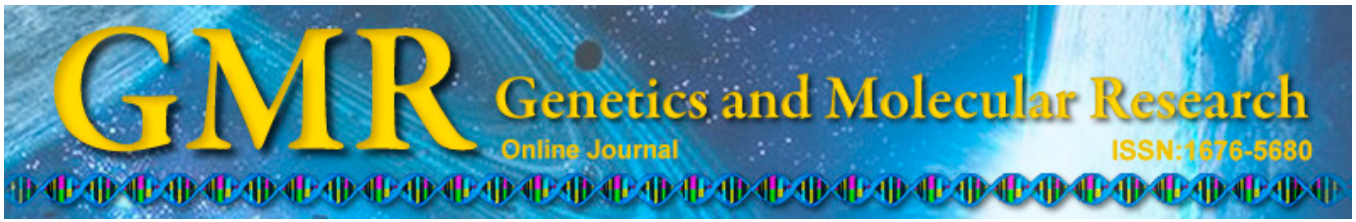

\title{
Construction of the mammalian expressing vector pEGFP-N1-P53 and its expression successful in chicken fibroblast cells and blastoderm
}

Z. Song ${ }^{1}$, Z.H. Li ${ }^{1}$, X.Q. Lei ${ }^{1}$, T.S. Xu ${ }^{1}$, X.H. Zhang', Y.J. Li ${ }^{1}$, G.M. Zhang ${ }^{2}$, S.M. Xi ${ }^{3}$, Y.B. Yang ${ }^{1}$ and Z.G. Wei ${ }^{1}$

${ }^{1}$ College of Animal Science, Henan University of Science and Technology, Luoyang, Henan, China

${ }^{2}$ The First Affiliated Hospital of Henan University of Science and Technology, Luoyang, Henan, China

${ }^{3}$ Institute of Medicine, Henan University of Science and Technology,

Luoyang, Henan, China

Corresponding authors: X.Q. Lei / T.S. Xu

E-mail: xueqinlei@163.com / xuts98@163.com

Genet. Mol. Res. 14 (1): 931-939 (2015)

Received January 14, 2014

Accepted November 28, 2014

Published February 2, 2015

DOI http://dx.doi.org/10.4238/2015.February.2.16

ABSTRACT. The enhanced green fluorescent protein (EGFP) pEGFPN1-P53 eukaryotic expression vector, which contains the human tumor suppressor $p 53$, was constructed and transfected into chicken fibroblast cells and stage-X blastoderm to analyze the transfection efficiency. The complementary DNA of the human $p 53$ gene was cloned by reverse transcription-polymerase chain reaction from human peripheral blood and inserted into the pEGFP-N1 vector by HindIII and BamHI double digestion. The pEGFP-N1-P53 vector was transfected into chicken embryo fibroblasts by Lipofectamine ${ }^{\mathrm{TM}} 2000$ liposomes, and the transfection efficiency was analyzed by fluorescence microscope after $36 \mathrm{~h}$ of transfection. The stage-X blastoderm was also transfected by 
blastoderm injection using Lipofectamine ${ }^{\mathrm{TM}} 2000$ liposomes at room temperature after 12-24 h; then hatching occurred until seventh day, and the transfection efficiency was analyzed by fluorescence microscope in the dead embryo. A total of 90 hatching eggs were transfected by the pEGFP-N1-P53 vector, and 20 chicken embryos expressed the reporter gene, which indicated that recombinant pEGFP-N1-P53 could be transfected and expressed in stage-X blastoderm by liposomes. Chicken embryo fibroblasts were transfected and expressed the reporter gene. The pEGFP-N1-P53 vector was constructed successfully and could be transfected and expressed in chicken embryo fibroblasts and stage- $\mathrm{X}$ blastoderms efficiently.

Key words: Chicken; pEGFP-N1; Chicken embryo fibroblasts; Chicken stage-X blastoderm

\section{INTRODUCTION}

The green fluorescence protein (GFP) is a type of monomer photoprotein that is composed of 238-amino acid residues and has a molecular weight of 27-30 kDa (Prasher et al., 1992; Ormö et al., 1996; Yang et al., 1996; Henderson et al., 2009); it has been used as a reporter in a broad range of applications, including the determination of gene expression in diverse organisms and subcellular protein localization. The EGFP has been produced by replacing Thr and Leu with Ser65 and Phe64, respectively. Moreover, it shows enhanced fluorescence strength that is 35 times greater than that of the GFP; it also exhibits improved sensitivity for the reporter gene (Cormack et al., 1996). pEGFP-N1 is a eukaryotic expression vector encoding EGFP, the MCS of which locates at the $\mathrm{N}$ terminus of EGFP. In addition, EGFP has a maximum excitation and emission of 488 and $507 \mathrm{~nm}$, respectively, which is compatible with most fluorescence filters.

For in vivo studies, EGFP has already been established in various systems (Dabiri et al., 1999; Hunt et al., 2002). Bouvet et al. (2002) successfully used EGFP for real-time optical imaging of primary tumor growth and metastatic events in pancreatic cancer. Yamamoto et al. (2003) demonstrated real time imaging of fibrosarcoma lung metastases with EGFP, and Yang et al. (2001) used EGFP for optical imaging of tumor angiogenesis of pancreatic and prostate cancers. The results of these studies indicate that EGFP is suitable for marking the expression of the ectogenous gene in vivo.

Although recombinant viruses are currently used for this purpose because of their high transfection activity, the use of nonviral vectors is still desired from the viewpoint of safety. Currently, how to transfer exogenous genes into cells effectively and safely is the major limitation in gene therapy research. Liposomes, which are respective complexes of cationic liposomes with DNA, are viewed as promising nonviral gene vectors.

The human $p 53$ gene contains 11 exons that code a protein of 393-amino acid residues. Although the $p 53$ gene was originally regarded as a dominant oncogene, it rapidly became clear that mutant $p 53$ genes were involved in these early studies. Subsequent studies have clearly demonstrated that the wild-type $p 53$ acts as a tumor suppressor gene (Chang et al., 1993). The ability of $p 53$ to efficiently inhibit cell proliferation by blocking cell cycle 
progression and promoting apoptotic cell death provides a clear mechanism to stem tumor cell growth and, thus, inhibit cancer development. The tumor suppressor $p 53$ gene is mutated or deleted in many immortal and tumor cell lines, with functional loss in $>50 \%$ of all human tumors (Levine et al., 1994).

The ability to direct genetic changes at the molecular level has resulted in a revolution in biology. The earliest reports on the successful production of transgenic chickens involved the use of vectors derived from avian retroviruses (Salter et al., 1987; Bosselman et al., 1989). In this study, we used liposomal transfection of the pEGFP-N1 vector to express the human $p 53$ protein in chicken embryos (Inouye and Tsuji, 1994). This vector contains a neomycin/ kanamycin resistance gene of $\operatorname{Tn} 5$ and polyadenylation signals from the herpes simplex thymidine kinase gene. It allows stably transfected eukaryotic cells to be selected using G418 (Cormack et al., 1996; Tseng et al., 1997).

In the present study, we tried to explicitly demonstrate the usefulness of the pEGFP-N1-P53 expression system in the transgenic chicken embryo model using the EGFP marker gene. The results of this study demonstrated successful production of transgenic chicken embryos that expressed the EGFP protein. This transgenic chicken embryo model will aid studies on animal bioreactors and gene therapy where controlled expression of potential therapeutic genes is needed.

\section{MATERIAL AND METHODS}

\section{Clone of the human p53 cDNA fragment}

The primers of $p 53$ were designed with reference to the GenBank sequence of the human tumor suppressor gene (accession No. NW_926584.1). The primers were joined to the restriction sites of HindIII and BamHI. The human $p 53$ cDNA fragment was obtained by RTPCR from the total RNA of human peripheral blood using TRIzol.

The forward primer was 5'-CCCa HindIII agcttATGGAGGAGCCGCAGTC3', and the reverse primer was $5{ }^{\prime}-\mathrm{CGCg}$ procedure used in this study was as follows: predenaturation at $94^{\circ} \mathrm{C}$ for $5 \mathrm{~min} ; 5$ cycles of denaturation at $94^{\circ} \mathrm{C}$ for $30 \mathrm{~s}$, annealing at $65^{\circ} \mathrm{C}$ for $30 \mathrm{~s}$, and an extension at $72^{\circ} \mathrm{C}$ for $90 \mathrm{~s} ; 35$ cycles of DNA denaturation at $94^{\circ} \mathrm{C}$ for $30 \mathrm{~s}$, annealing at $68^{\circ} \mathrm{C}$ for $30 \mathrm{~s}$, and an extension at $72^{\circ} \mathrm{C}$ for $90 \mathrm{~s}$; followed by a 10 -min final extension at $72^{\circ} \mathrm{C}$.

\section{Construction and identification of the pEGFP-N1-P53 expression vector}

The pEGFP-N1 vector and $p 53$ cDNA fragment were digested by the HindIII (Takara, Dalian, China) and BamHI (Takara) restriction enzymes and then ligated by the T4 DNA ligase (Takara) to construct the pEGFP-N1-P53 eukaryotic expression vector. The pEGFP-N1-P53 DNA was transformed into competent cells derived from Escherichia coli JM109 (provided by the Central Laboratory of Henan University of Science and Technology); the white single colonies were collected, placed into liquid LB culture medium, and incubated on a shaking table overnight. Finally, the recombinant extraction plasmid, pEGFP-N1-P53, was digested by HindIII and BamHI to verify its accuracy (Figure 1) and then detected by DNA automatic sequencing analysis. 


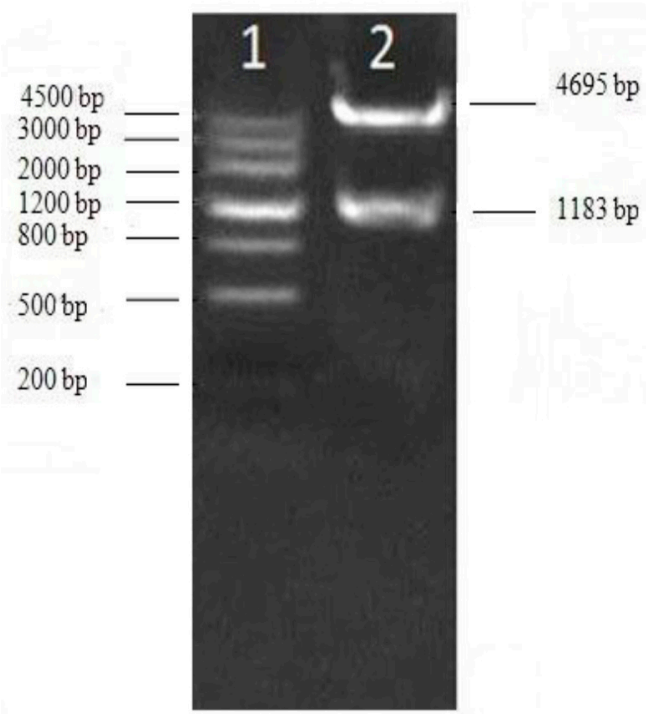

Figure 1. Agarose gel electrophoresis of the product of pEGFP-N1-P53 by enzyme digestion. Lane 1: DNA Marker III; lane 2: identification of the product of pEGFP-N1-P53 by enzyme digestion.

\section{Chicken embryo fibroblast (CEF) culture}

CEFs were prepared from 9- to 10-day-old embryos by methods previously described (Lawlor and O'Brien, 1994). The embryos were placed on the dish under sterile conditions; then, the heads, toes, wings, and several internal organs were removed. The tissues were washed in phosphate-buffered saline 4-5 times to remove surface blood and then washed again in DMEM. A small amount of the DMEM was left on the culture dish. Ophthalmic scissors were used to repeatedly cut the tissues until the tissue pieces were $\sim 1 \mathrm{~mm}$ in size. Subsequently, the cells were harvested by cell sieve after trypsin treatment, centrifuged for $5 \mathrm{~min}$ at $1500 \mathrm{rpm}$ to remove the trypsin digestive juices, and resuspended on culture DMEM plastic Petri dishes ( $2 \times 10^{6}$ in $9 \mathrm{~mL}$ per dish). The Petri dishes were inverted at $37^{\circ} \mathrm{C}$ in a $5 \% \mathrm{CO}_{2}$ incubator for $4 \mathrm{~h}$; then, the growth medium ( $2 \mathrm{~mL}$ DMEM) was added on the same plastic Petri dishes as that of the incubation medium (5-mL Petri dish cultures) for secondary culture.

\section{Preparation and transfection of the chicken embryo fibroblast transfection solution}

The transfection solution contained 2 different ingredients. Solution 1 contained 240 $\mu \mathrm{L}$ DMEM without fetal bovine serum (FBS) and $10 \mu \mathrm{L}$ Lipofectamine $^{\mathrm{TM}} 2000$ (Invitrogen, Shanghai, China) per well (total volume of $250 \mu \mathrm{L}$ incubated for $5 \mathrm{~min}$ ); solution 2 contained DMEM without FBS and $1.0 \mu \mathrm{g}$ plasmid per well (total volume of $250 \mu \mathrm{L}$ ). The 2 different solutions were mixed and allowed to stand still $20 \mathrm{~min}$ at room temperature.

For transfection, CEF cells ( $1 \times 10^{5}$ cells/well) were seeded on a 24 -well plate and incubated in DMEM with $10 \%$ FBS for $24 \mathrm{~h}$ before transfection. After the medium was removed and replaced with DMEM without FBS, various CEF/DNA complexes ( $1 \mu \mathrm{g}$ DNA/well) were added to the cells for $6 \mathrm{~h}$. Subsequently, the medium was replaced with the DMEM containing 
$10 \% \mathrm{FBS}$, and the cells were incubated for another $18 \mathrm{~h}$ at $37^{\circ} \mathrm{C}$ with $5 \% \mathrm{CO}_{2}$. The secondary culture incubation time was $24-48 \mathrm{~h}$; then, the transfection efficiency was evaluated.

\section{Microinjection of the pEGFP-N1-P53 vector into chicken embryo}

Only eggs with a normal shape that weighed $\sim 60 \mathrm{~g}$ were used. These eggs were positioned with their sides facing upward for 12-24 h at room temperature in order to fix the blastoderm position. After swabbing the shell with $70 \%$ alcohol, a $5 \times 5-\mathrm{mm}^{2}$ window was made in the equatorial plane of the eggshell using a fine drill, which was followed by removal of the small shell membrane inside the window with fine forceps and a surgical blade. Two microliters of solution, which contained solutions 1 and 2, was injected into the central part of the subgerminal cavity using a microinjection pipette. After injection, the window was sealed with the eggshell membrane and egg white.

\section{Egg incubation}

After microinjection, the sealed eggs were incubated at $38^{\circ} \mathrm{C}$ with $50-55 \%$ relative humidity and a rocking motion every $2 \mathrm{~h}$ at a $45^{\circ}$ angle for 18 days. They were subsequently incubated at $37.6^{\circ} \mathrm{C}$ and $65-75 \%$ relative humidity without rocking until hatching.

\section{RESULTS}

\section{Expression of the EGFP gene in transgenic fibroblasts}

After $36 \mathrm{~h}$ of culture at $37^{\circ} \mathrm{C}$ in a $5 \% \mathrm{CO}_{2}$ incubator, the CEF cell line was observed by fluorescence microscope (400X, ECLIPSE TE2000-U, Nikon, Japan). No fluorescence was observed in the control groups, while strong green fluorescence was observed in the CEF cell line transfected with the recombinant plasmid pEGFP-N1-P53 (Figure 2).
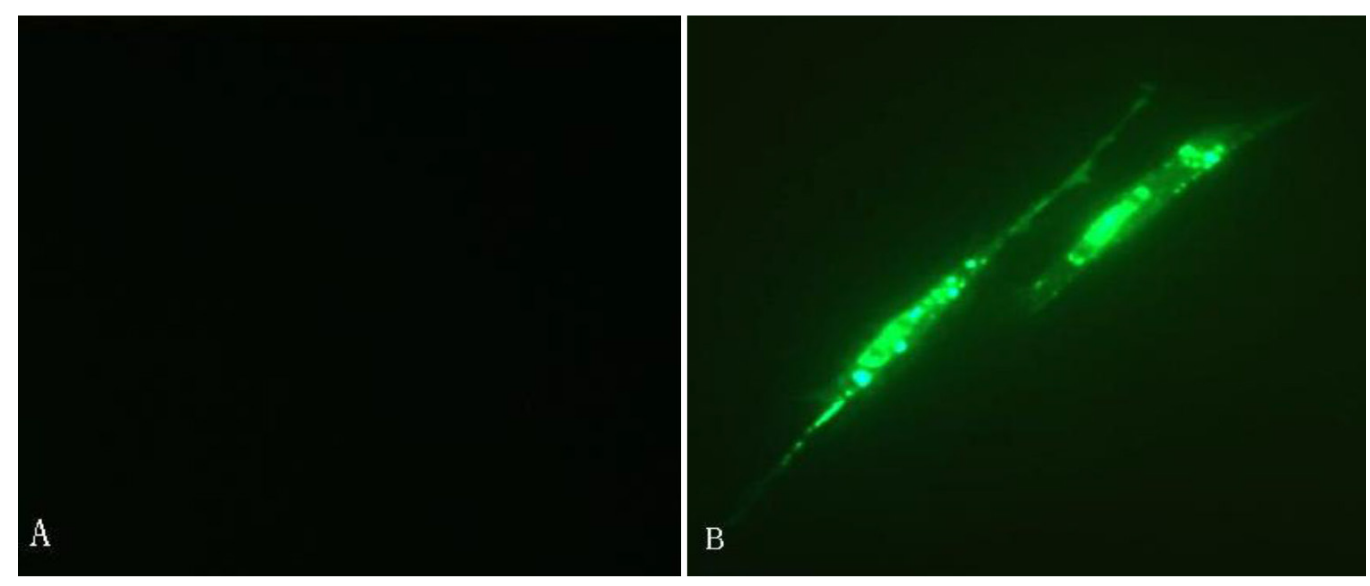

Figure 2. Observation of the chicken embryonic fibroblast (CEF) cell line by fluorescence microscope. A. Control group. B. Transfection with pEGFP-N1-P53 vector at $36 \mathrm{~h}$. After $36 \mathrm{~h}$ of culture at $37^{\circ} \mathrm{C}$ in a $5 \% \mathrm{CO}_{2}$ incubator, the CEF cell line was observed by fluorescence microscope (400X, ECLIPSE TE2000-U, Nikon). 


\section{Expression of the EGFP gene in transgenic embryo}

A total of 90 eggs were microinjected with the pEGFP-N1-P53 vector. On days 3 and 7 of hatching, deceased embryos were removed. The cumulative embryo death rates for 0-3 days and 4-7 days were 47.8 and $65.6 \%$, respectively (Table 1 ).

Table 1. Survival and death rates of the injected embryos after incubation.

\begin{tabular}{lcccc}
\hline Days & Dead embryos $(\mathrm{N})$ & Surviving embryos $(\mathrm{N})$ & Embryo death rate & Embryo survival rate \\
\hline $0-3$ & 43 & 47 & $47.8 \%$ & $53.2 \%$ \\
$4-7$ & 16 & 31 & $65.6 \%$ & $34.4 \%$ \\
\hline
\end{tabular}

\section{Detection of the transfection efficiency}

After 7 days of hatching, embryo tissue samples were collected and smeared to test the expression of the GFP by fluorescence microscope (400X, ECLIPSE TE2000-U, Nikon). Microscopic analysis indicated the presence of a strong green fluorescence in the deceased embryos, while no fluorescence was observed for the control groups (Figure 3). This indicates that the fluorescent proteins were expressed in the deceased chicken embryos.

A total of 90 transfected chicken embryos, including 59 deceased embryos and 31 surviving embryos, were detected by fluorescence microscope; 20 embryos (13 deceased and 7 surviving) were detected to express the GFP; the positive rate in the deceased embryos was $6 \%$ higher than that in the surviving embryos (Table 2).

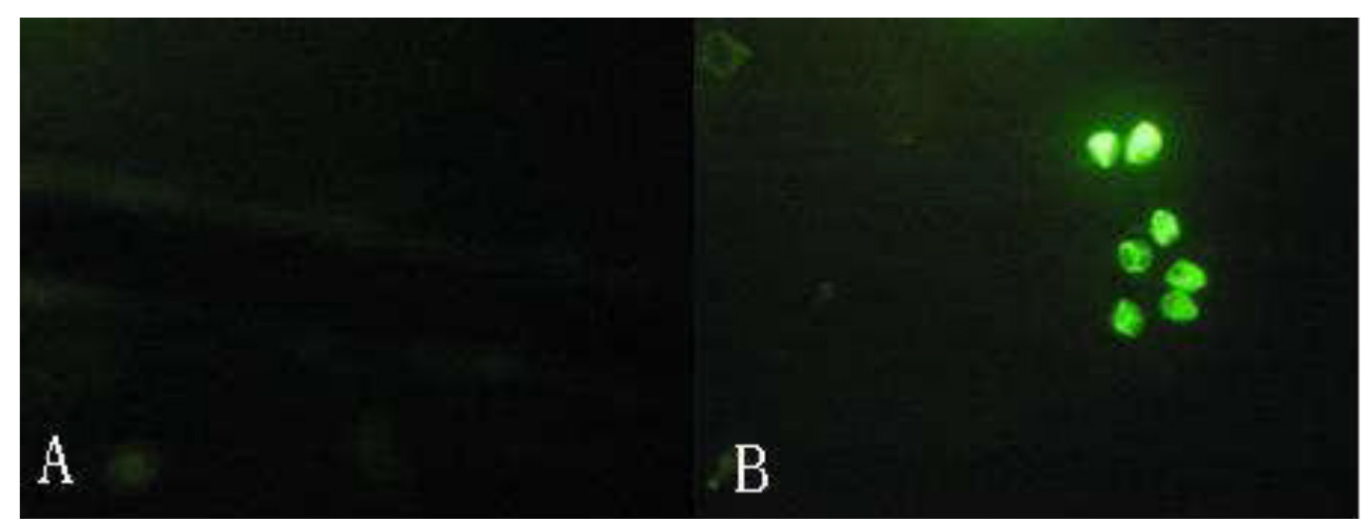

Figure 3. Enhanced green fluorescent protein in deceased embryos. A. Control group; B. deceased embryos. After 7 days of hatching, embryo tissue samples were collected and a smear was made to test the expression of the green fluorescent protein by fluorescence microscope (400X, ECLIPSE TE2000-U, Nikon).

Table 2. Detection rate of EGFP in chicken embryos.

\begin{tabular}{llcr}
\hline Embryo type & N & No. of positive embryos & Rate of positive embryos (\%) \\
\hline Deceased embryos & 59 & 13 & 22 \\
Surviving embryos & 31 & 7 & 16 \\
\hline
\end{tabular}




\section{DISCUSSION}

pEGFP-N1 is a type of eukaryotic expression vector encoding EGFP, the MCS of which locates at the $\mathrm{N}$ terminus of EGFP. However, to our knowledge, no transgenic chicken expressing the EGFP gene has been reported, presumably due to the cytotoxicity of the gene product (Perry et al., 1999). Therefore, the significance of this study stems from the fact that it ultimately provides a versatile tool for furthering our understanding of chicken embryonic development.

In the present study, we attempted to generate transgenic chickens expressing the EGFP gene. Compared to other marker genes, such as E. coli LacZ and B-lactamase, it is generally accepted that EGFP has the advantage of affording simple and visual confirmation of gene expression without compromising sample viability. EGFP could undergo autocatalysis to form a chromophore without any cofactors, emitting a green fluorescence once it is excited by near ultraviolet or blue lights (Figures 2 and 3). Therefore, EGFP has been widely used in the biomedical field as a multi-functional tool for some qualitative or quantitative investigations on protein interactions, enzymatic activities, drug monitoring (Takanishi et al., 2006; Meima et al., 2007), gene expression (Ueta et al., 2005; Suzuki et al., 2008), protein localization (Butera et al., 2005; Peckham et al., 2006; Magliery and Regan, 2006), evaluation of the therapeutic effects of tumor vaccines, fluorescence labeling of targeted proteins, and more (Warmann et al., 2005; Fujio et al., 2006; Shibata et al., 2007; Zhuang et al., 2008; Suzuki et al., 2009). These papers indicate that EGFP is suitable for in vivo and in vitro studies; thus, in this study, the EGFP vector was selected to express exogenous proteins in vivo.

The method used in this study was characterized by its simplicity as follows: injecting fertilized eggs with a reaction mixture of plasmid DNA and liposomes. Several methodologies can be used for the production of transgenic animals. Liposome/DNA delivery methods are other techniques under study for introducing cloned DNA into cells and embryos. Liposomes are small vesicles consisting of membrane-like lipid layers that can actually protect foreign DNA from digestion by proteases and DNAses (Felgner et al., 1987). However, cationic liposome-mediated transfection is greatly inhibited by surface binding to cationic lipid/DNA complexes (lipoplexes) of serum proteins/polyanionic molecules in the blood, which leads to structural reorganization, aggregation and/or dissociation of the complexes, weakened electrostatic interactions with cell membranes, and reduced transfection efficiency (Crook et al., 1998; Zhang and Anchordoquy, 2004).

In transgenic animal production, the goal is to express an exogenous gene at high levels, but experience has shown that constitutively high expression levels of an exogenous gene usually result in severe physiological disturbances. The introduction of an exogenous gene often leads to the death of an embryo, which is one of the main reasons that the detection rate of the GFP was higher in the deceased embryos than that of the surviving embryos in the current study. Another reason for the higher detection rate of the enhanced GFP in deceased embryos may be that the injury caused by microinjection was notable in the deceased embryos because the location of microinjection is more important to the survival of chicken embryos. In addition, during the embryonic period, most of the transgenic chicken embryos show developmental stagnation; many surviving transgenic chickens are frail, experience leg paralysis and standing instability, so the transgenic chicken were easy death.

Currently, no studies are available regarding the production of transgenic embryos in chickens with the exogenous $p 53$ gene. Therefore, the significance of this study stems from 
the fact that it is a successful report on the production of transgenic chicken embryos expressing the human $p 53$ gene. The results may be helpful in establishing a model system for efficient transgenic chicken embryo production. It also lays the foundation for further studies on transgenic chicken embryo development and the efficient production of transgenic chickens as bioreactors.

\section{ACKNOWLEDGMENTS}

(\#072300430010).

\section{REFERENCES}

Bosselman, RA, Hsu R, Boggs T, Hu S, et al. (1989). Germline transmission of exogenous genes in the chicken. Science 243: 533-535.

Bouvet M, Wang J, Nardin SR, Nassirpour R, et al. (2002). Real-time optical imaging of primary tumor growth and multiple metastatic events in a pancreatic cancer orthotopic model. Cancer Res. 62: 1534-1540.

Butera D, Piazza RM, McLane MA, Chammas R, et al. (2005). Molecular engineering of an EGFP/disintegrin-based integrin marker. Toxicon 46: 178-184.

Chang F, Syrjänen S, Tervahauta A and Syrjänen K (1993). Tumorigenesis associated with the $p 53$ tumor suppressor gene. Br. J. Cancer 68: 653-661.

Cormack BP, Valdivia RH and Falkow S (1996). FACS-optimized mutants of the green fluorescent protein (GFP). Gene 173: 33-38.

Crook K, Stevenson BJ, Dubouchet M and Porteous DJ (1998). Inclusion of cholesterol in DOTAP transfection complexes increases the delivery of DNA to cells in vitro in the presence of serum. Gene Ther. 5: 137-143.

Dabiri GA, Ayoob JC, Turnacioglu KK, Sanger JM, et al. (1999). Use of green fluorescent proteins linked to cytoskeletal proteins to analyze myofibrillogenesis in living cells. Methods Enzymol. 302: 171-186.

Felgner PL, Gadek TR, Holm M, Roman R, et al. (1987). Lipofection: a highly efficient, lipid-mediated DNA-transfection procedure. Proc. Natl. Acad. Sci. U S A 84: 7413-7417.

Fujio T, Fujihara H, Shibata M, Yamada S, et al. (2006). Exaggerated response of arginine vasopressin-enhanced green fluorescent protein fusion gene to salt loading without disturbance of body fluid homeostasis in rats. $J$. Neuroendocrinol. 18: 776-785.

Henderson JN, Gepshtein R, Heenan JR, Kallio K, et al. (2009). Structure and mechanism of the photoactivatable green fluorescent protein. J. Am. Chem. Soc. 131: 4176-4177.

Hunt L, Batard P, Jordan M and Wurm FM (2002). Fluorescent proteins in animal cells for process development: optimization of sodium butyrate treatment as an example. Biotechnol. Bioeng. 77: 528-537.

Inouye S and Tsuji FI (1994). Aequorea green fluorescent protein. Expression of the gene and fluorescent characteristics of the recombinant protein. FEBS Lett. 341: 277-280.

Lawlor SM and O'Brien NM (1994). Development of an in vitro cell culture model to investigate the induction and quantification of oxidative stress and its inhibition by alpha-tocopherol. Toxicol. In Vitro 8: 67-73.

Levine AJ, Chang A, Dittmer D, Notterman DA, et al. (1994). The 553 tumor suppressor gene. J. Lab. Clin. Med. 123: 817-823.

Magliery V and Regan L (2006). Reassembled GFP: detecting protein-protein interactions and protein expression patterns. Meth. Biochem. Analysis. 47: 391-405.

Meima ME, Weening KE and Schaap P (2007). Vectors for expression of proteins with single or combinatorial fluorescent protein and tandem affinity purification tags in Dictyostelium. Prot. Expr. Pur. 53: 283-288.

Ormö M, Cubitt AB, Kallio K, Gross LA, et al. (1996). Crystal structure of the Aequorea victoria green fluorescent protein. Science 273: 1392-1395.

Peckham GD, Bugos RC and Su WW (2006). Purification of GFP fusion proteins from transgenic plant cell cultures. Prot. Expr. Pur. 49: 183-189.

Perry AC, Wakayama T, Kishikawa H, Kasai T, et al. (1999). Mammalian transgenesis by intracytoplasmic sperm injection. Science 284: 1180-1183.

Prasher DC, Eckenrode VK, Ward WW, Prendergast FG, et al. (1992). Primary structure of the Aequorea victoria green 
fluorescent protein. Gene 111: 229-233.

Salter DW, Smith EJ, Hughes SH, Wright SE, et al. (1987). Transgenic chickens: insertion of retroviral genes into the chicken germ line. Virology 157: 236-240.

Shibata M, Fujihara H, Suzuki H, Ozawa H, et al. (2007). Physiological studies of stress responses in the hypothalamus of vasopressin-enhanced green fluorescent protein transgenic rat. J. Neuroendocrinol. 19: 285-292.

Suzuki H, Kawasaki M, Ohnishi H, Nakamura T, et al. (2008). Regulatory mechanism of the arginine vasopressinenhanced green fluorescent protein fusion gene expression in acute and chronic stress. Peptides 30: 1763-1770.

Suzuki H, Onaka T, Kasai M, Kawasaki M, et al. (2009). Response of arginine vasopressin-enhanced green fluorescent protein fusion gene in the hypothalamus of adjuvant-induced arthritic rats. J. Neuroendocrinol. 21: 183-190.

Takanishi CL, Bykova EA, Cheng W and Zheng J (2006). GFP-based FRET analysis in live cells. Brain Res. 1091: $132-$ 139.

Tseng WC, Haselton FR and Giorgio TD (1997). Transfection by cationic liposomes using simultaneous single cell measurements of plasmid delivery and transgene expression. J. Biol. Chem. 272: 25641-25647.

Ueta Y, Fujihara H, Serino R, Dayanithi G, et al. (2005). Transgenic expression of enhanced green fluorescent protein enables direct visualization for physiological studies of vasopressin neurons and isolated nerve terminals of the rat. Endocrinology 146: 406-413.

Warmann SW, Fuchs J, Seitz G, Ruck P, et al. (2005). New trends in tumor biology: transfection of a human hepatoblastoma cell line with green fluorescent protein. J. Pediatric. Surg. 40: 653-657.

Yamamoto N, Yang M, Jiang P, Tsuchiya H, et al. (2003). Real-time GFP imaging of spontaneous HT-1080 fibrosarcoma lung metastases. Clin. Exp. Metastasis 20: 181-185.

Yang F, Moss LG and Phillips GN Jr (1996). The molecular structure of green fluorescent protein. Nat. Biotechnol. 14: 1246-1251.

Yang M, Baranov E, Li XM, Wang JW, et al. (2001). Whole body and intravital optical imaging of angiogenesis in orthotopically implanted tumors. Proc. Natl. Acad. Sci. U S A. 98: 2616-2621.

Zhang Y and Anchordoquy TJ (2004). The role of lipid charge density in the serum stability of cationic lipid/DNA complexes. Biochim. Biophys. Acta 1663: 143-157.

Zhuang R, Zhang Y, Zhang R, Song C, et al. (2008). Purification of GFP fusion proteins with high purity and yield by monoclonal antibody-coupled affinity column chromatography. Prot. Expr. Pur. 59: 138-143. 